\title{
Relocation Consideration By Central City Manufacturing Firms $\dagger$
}

\author{
Rodney A. Erickson and Michael J. Wasylenko*
}

Accompanying the postwar dispersal of business establishments and employment in metropolitan areas has been an increasing interest in the magnitude and nature of intrametropolitan industrial relocation. Both macro studies of job losses in core areas $[1,10,13]$ and micro studies of establishment relocation $[2,5,14]$ have characterized the resulting research stream. Research on industrial relocation during the past decade has been greatly aided by the availability of data for establishments through Dun and Bradstreet's "Market Identifier" file. Early studies by Struyk [21], James and Hughes [9], and Struyk and James [22] provided considerable insight into the general characteristics of relocating establishments, e.g., their employment size, industrial sector, and the geographic areas of origin and destination. Paralleling this empirical inquiry has been a growing interest in the decision-making process underlying relocation, typified by the large, survey-based studies of Schmenner [5] and Schmidt [18].

For the most part the above research has concerned itself with mover establishments and the questions "who moves?, why do they move?, and to where do they relocate?" Comparatively little attention has been devoted to the counterpart group-the non-movers-despite the fact that they clearly make up the vast majority of industrial establishments in the metropolitan area. There are numerous questions that one might ask about this latter group of firms: What proportion of them has seriously considered relocation? Are there distinguishing features that characterize those firms which are or may have considered relocation from those firms which have not? Are these features primarily internal to an establishment's operation or external and influenced by exogenous forces?

In this paper we attempt to provide some answers to these questions by analyzing a set of survey responses from non-mover industrial establishments located in the city of Milwaukee. A framework, including a review of the limited related research that has been accomplished, and key variables are first presented. A description of survey procedures and variables follows. The empirical analysis uses probit analysis to test for significant

†The data for this analysis were gathered in conjunction with a project supported by the National Science Foundation under Grant No. SOC78-08476.

*The authors are, respectively, Associate Professor of Geography and Business Administration and Associate Professor of Economics at The Pennsylvania State University, University Park, Pennsylvania. 
differences in the characteristics of establishments and their surroundings between those non-movers which seriously considered relocation to another part of the city and those which did not. ${ }^{1}$

Schmenner [16] has argued that, from a public policy perspective, central city government should place relatively less emphasis on attracting new employers and focus more attention on keeping those establishments which are currently located in the city. This latter emphasis includes doing what can be done governmentally to provide the kind of environment wherein industrial establishments can expand their operations. Answers to the questions concerning non-movers posed above may prove useful in better evaluating and targeting public policies for central city economic development.

\section{RESEARCH FRAMEWORK}

It is universally agreed that the decision-making process surrounding establishment relocation is a very complex one. Firms typically consider relocating their facilities if they have operating difficulties at their present site. The costs of moving the establishment, the time spent planning the move, and the production time lost during the move are typically high; similarly, firms can generally obtain only approximate information on the amount of additional profits that will accrue at the new location [11]. Given the uncertainty surrounding the new locations and the costs of the move, firms are likely to move their facilities only if the difficulties at the present site cannot be remedied. Thus, establishments enjoying location advantages at their present sites, such as highway access and proximity to labor, suppliers and customers, may be less likely to consider seriously relocation despite some difficulties at the existing site [19].

The relocation decision is properly viewed as one of a series of investment decisions facing the firm [23]. Contrary to the popular impression that relocation is considered only a very few times in the life of the firm, the location/relocation question may be reviewed annually or every few years by management in the course of making investment decisions.

It appears that a substantial proportion of firms seriously considers relocation. Gruber [7] found in a survey of Atlanta industrial establishments that about 31 percent of those responding indicated a "high probability" of relocation during the next five years. However, research indicates that a much smaller percentage of industrial establishments actually undertakes relocation $[5,21,22] .{ }^{2}$ Most moves are made only reluctantly and over relatively short distances [14] which is further evidence of the considerable inertia embodied in existing locations.

Most previous research has regarded the relocation decision as being influenced by factors both internal and external to the establishment's operation. Internal factors are those elements over which the firm exercises control or is an outcome of the firm's actions over a past time period. Such internal factors may be the size of the establishment in terms of output or employment, the nature of products produced for market, the growth rate of the establishment, or the organizational structure of the 
enterprise. Internal factors also include the characteristics of the site itself and the nature of the production space utilized by the establishment. External factors are those elements over which the firm cannot exercise control, such as the actions of competition, the locational patterns of inputs and markets, and the characteristics of the local area surrounding the establishment's site.

\section{Internal Factors}

Among the internal factors most frequently linked to relocation is the size of the establishment. Output or employment magnitude is often a good surrogate for fixed investment in plant and equipment and, in general, the larger the size the less likely the establishment is to relocate. Gruber [ 7$]$ found that larger establishments expressed a lower probability of relocating than smaller ones; ${ }^{3}$ similarly, Schmenner $[15]$ also found employment size to be a good variable to differentiate between mover and stationary plants in Cincinnati. Not only does size of establishment indicate larger direct costs of moving a plant's operations, it may also be related to other internal factors which significantly influence the prospects of relocation. Schmenner [15] has argued that smaller firms typically display less "established" input and output linkages than do larger ones and, therefore, relocating is less likely to disrupt longstanding production and marketing relationships.

Establishment size is also likely to be related to length of tenure at a particular site, inasmuch as a significant proportion of firms have experienced both output and employment expansion at an occupied site. Thus, years at site may be directly related to size of establishment and one might assume that establishments with longer tenure would be less likely to consider relocation. But the relationship is not as straightforward as it might appear. On one hand, tenure at site may indicate that establishments have a long-standing and rather fixed pattern of input and output linkages that, if broken by relocation, would impose considerable costs on the firm. On the other hand, a longer tenure at site may indicate that plant and equipment have been depreciated to a greater extent and significant investment advantages may exist for the firm to relocate to an alternative site. The prospective move may permit new production technology or layouts to be incorporated into the plant and equipment investment and represent a significant stimulus to the consideration of such an alternative. In general, one would be most likely to observe a positive relationship between tenure at site and relocation consideration.

A related factor that must be considered is whether or not the firm owns or rents the existing building and property on its plant site. In many cases leased premises make it easier and less costly to relocate, negating the necessity of depreciating a large fixed investment in plant. Potential lease termination also raises the possibility of a "forced move." Larger firms are more likely to own their facilities, while smaller firms are more likely to be renters. Lessees probably have been at a particular site a shorter period of time than the average firms which own their production facilities [20]. 
Gruber [7] found that, for Atlanta establishments, more than twice as high a proportion of establishments which leased their building(s) considered relocation very probable.

An internal factor which may be related to relocation consideration and which has received increasing attention from researchers in recent years relates to the corporate or organizational structure of which the establishment is a part. Because the establishment is part of a larger operation, the enterprise may have considerably more flexibility in determining the investment strategy related to an individual plant $[3,17]$. Alternatives to relocation include the reallocation of production to other units in the enterprise or changing the nature of the production carried on at a particular plant. Thus, one might expect that establishments in larger and more complex organizations would possess more production change alternatives to relocating a plant than would the enterprise operating only one plant.

The prospect of rapid establishment growth has often been cited as a primary internal factor prompting management or an owner-manager to consider relocation of a plant. Townroe [23], in his classic article on location choice and the individual firm, has cited firm growth as among the most critical elements influencing management policy and the resulting investment strategy of the firm. Growth of output is important inasmuch as it may imply a healthier financial situation for the firm and its plant(s) which makes a potential relocation more feasible. Thus, in general, one would expect that firms exhibiting low rates of growth in previous periods would be far less likely to ponder relocation, unless that relocation would result in significant cost savings, such as movement to smaller and less costly facilities which could be more fully utilized in the production processes [23].

High growth rates of output and employment, however, may not be as closely associated with relocation consideration as might be expected. If existing facilities are adequate to handle both actual and anticipated growth, there may be little incentive to consider seriously the prospect of relocation. Gruber's [7] study of Atlanta establishments found little relationship between high growth and the likelihood of relocation. Firms that expected substantial increases in sales over the next five years were no more likely (in fact, much less likely) to consider relocation highly probable than those firms with stable or declining sales forecasts.

A focal element in Townroe's [23] framework that is relevant to relocation consideration is the role of potential expansion room on-site. Growth prospects, and the investment strategy used to support that management policy, generally create pressures for additional space. To the extent that the establishment has sufficient unused space, or can reorganize existing space use to meet the needs for expanded production, relocation is less likely to be considered. It appears that, in general, most firms prefer to expand on-site if possible, thereby avoiding the direct costs and disruptions to supply and market channels that accompany relocation. This factor helps to explain why a far smaller proportion of those firms which consider relocation actually opt for that alternative and also helps to 
explain why the vast majority of moves are over short distances $[5,14,15]$. If inadequate space for on-site expansion exists, relocation consideration is much more likely and, at least to some extent, the growth rate factor may be interrelated with the prospect of on-site room for expansion. Even though a firm may experience and/or project a high growth rate for its plant, it is likely to remain at its present location if expansion room exists.

Another internal factor which has frequently been cited as contributing to relocation consideration is the inadequacy of the building design itself to accommodate the firm's production. The typical scenario suggests that central area industrial plants occupy multi-storied buildings (largely constructed between 1880 and 1920) which are not conducive to the cost reductions made possible by single-story buildings with more modern production-line processes [8]. Yet, there is little more than anecdotal evidence suggesting that this is a critical factor affecting relocation consideration. Gruber [7] found that occupants of multi-storied buildings expressed no higher a probability of relocating than did those occupying single-story facilities. Thus, if a relationship exists, it may be a more complex one than has traditionally been thought.

\section{External Factors}

While the particular production function or combination of labor and other inputs used is a decision taken by firm management, the locational proximity of the establishment to labor and other production inputs and market channels represents a changing environment beyond the control, for the most part, of the firm. These considerations of proximity to labor, supplier firms, markets and other production and distribution factors have frequently formed the underpinnings for numerous models which purport to show the relocation of plants in relation to their changing macro environments $[8,12]$.

Theoretically, proximity to labor should be related to relocation consideration, especially among those plants with a high ratio of labor to total costs. Schmenner [15] found, for example, that Cincinnati firms which seriously considered relocating a plant were characterized by an increasing ratio of labor costs to sales over the past 10 years. Yet, other evidence suggests that labor issues are not as prominent in the decision-making process as one might expect. Gruber's [7] study found that firms which expressed problems with employee transportation were no more likely to consider relocation very probable than were firms which expressed no employee transportation problems.

Proximity to transportation facilities for inputs and outputs and associated reduced costs of transport also maintain a key position in the theory of why firms relocate to another site $[1,14]$. Firms whose plants have locations which prevent them from using the most economical means of transportation for inputs and outputs should, other things being equal, be more likely to consider relocation. Inasmuch as the vast majority of inputs and outputs are currently moved by truck transport, proximity to 
limited access highways and ease of utilizing the motor freight mode at the plant should be important relocation considerations. In Cincinnati [15], plants with a higher percent of their inputs delivered by truck were more likely candidates for relocation consideration. Similarly, Atlanta firms whose plants were at sites which prevented the use of more economical transportation modes were more likely to consider relocation to be very probable [7]. It should be noted, however, that the seeming ubiquity of truck transportation facilities raises the question as to how significant this factor might be to the overall picture of relocation consideration.

Other factors over which the firm exercises little if any control include the conditions (or changes in the conditions) of the local area surrounding the plant itself. Land value and land value increases (both relative and absolute) influence property assessments and tax burdens, as well as the potential market value of the site should movement occur and liquidation of the former site becomes necessary. Firms obviously may incur substantial opportunity costs when plants occupy land which has become more valuable for other purposes.

Changes in the characteristics of local areas may be important for marketing reasons, although the bulk of establishments usually serves a metropolitan, regional or national market. More important may be the higher incidence of crime or the lack of security for property or labor force in some, particularly core, areas of the city. Gruber's [7] study indicated that about four out of ten very probable movers expressed dissatisfaction with police services; however, three out of ten very probable movers expressed satisfaction with police services. Similarly, Erickson's [4] study of establishments leaving the Milwaukee central city for suburban sites found only a slightly higher rate of relocation in high crime areas, with the differences not being statistically significant. Thus, there is a continuing concern regarding not only the importance of various external factors used in the more traditional locational analyses, but also with the relative importance of these external factors in comparison to the various internal factors identified above.

\section{SURVEY AND DATA DESCRIPTION}

As part of a study of locational shifts of employment in the Milwaukee SMSA, a set of central city establishments which had not relocated since 1972 was surveyed by the authors in late $1979 .{ }^{4} \mathrm{~A}$ sample of 330 industrial establishments was randomly selected and a six-page questionnaire was mailed to each establishment. A total of 60 usable responses was returned. The questionnaire format followed closely that used by Schmenner [15] in his studies of Cincinnati and the New England Region.

The questionnaire was divided into seven parts eliciting information on company identity and the nature of the establishment and site, recent statistics and general changes over the past ten years, the character of the establishment's market, suppliers and concerns for transportation and proximity, as well as relocation consideration. ${ }^{5}$ Data used in the subsequent analysis were derived directly from the questionnaires with one notable 
exception. Data on the incidence of crimes against persons and property were obtained from the City of Milwaukee's Criminal Justice Program for census tracts covering the years 1973 and 1974. Crime incidence data were aggregated to 34 districts, each approximately equal in area to the largest census tracts; the average of the two years' figures was used in the analysis. ${ }^{6}$

\section{VARIABLES AND HYPOTHESIZED RELATIONSHIPS}

The empirical analysis reported here estimates how a variety of factors influences a firm's probability of seriously considering relocation. The dependent variable is a binary variable equal to one if a firm has seriously considered moving a plant and zero otherwise. Seventeen independent variables are used to represent factors influencing relocation consideration. Table 1 lists the variable names and definitions, and the hypothesized signs of the coefficients.

Nine independent variables are used to reflect factors internal to the firm that may affect relocation consideration. These variables reflect the operating characteristics of the plant including the site itself, its recent record in terms of growth, and the firm's organizational structure of which the plant is a part. Size of the plant (EMP) is measured by the reported number of employees. Inasmuch as larger plants likely reflect a greater fixed capital investment, high costs of moving, and the possible attenuation of established production (including labor force) and marketing relationships, the hypothesized sign is negative.

Independent dummy variables reflecting the plant's recent growth pattern include a high growth rate over the past 5 years (HIGROW), a low growth rate (LOGROW), and a change in the nature of operations at the plant over the past 10 years (CHGOPER). A dummy variable equal to one was used to specify a high growth rate of more than 15 percent per year and zero if otherwise. The expected sign of HIGROW is also negative since firms may be reluctant to leave sites at which they have experienced growth, providing that the present site can accommodate that growth. A dummy variable equal to one was used to specify a low growth rate of less than 5 percent per year or a decline, and zero if otherwise. Low growth plants are likely to be reluctant to move given that their operations appear to have stabilized; hence, the expected sign of LOGROW is negative. A change in operations of the plant is specified as a dummy variable equal to one where a fundamental change in operations has occurred, and zero if otherwise. Given that a change in operations or products creates potential difficulties at the present site, the expected sign of CHGOPER is positive.

Independent variables reflecting the plant's site itself include the length of tenure or years at the site (YRATSITE); a lease or ownership (LEASE) variable interacted with YRATSITE; the existence of room for expansion at the present site (EXPANDR); and the flexibility of the plant to operate in a variety of buildings, e.g., single-story or multi-storied (OPERA). A longer tenure at the present site suggests the greater possibility of obsolete or depreciated facilities and a positive sign for YRATSITE. Firms that rent 
their plant sites and have been at their present sites longer (YRATSITE* LEASE) are considered especially likely to ponder a move, resulting in an expected positive sign for this interaction variable. Plants which have only modest or no additional room for expansion (EXPANDR) (assigned a value of one) are more likely to consider relocation with a resulting hypothesized positive sign. An EXPANDR* HIGROW interaction variable was used in some specifications of the econometric model but the parameter was never statistically significant. Plants that can operate in any type of building(s) (assigned a value of one in the dummy variable specification) are more likely to consider relocation because the costs of constructing a new building or finding another suitable one are lower than for plants requiring specialized structures. One final internal variable (SEST) that is tested reflects whether or not the plant is a single-establishment firm or is part of a multiplant enterprise. A single-establishment firm (SEST assigned a value of one) may be more likely to consider relocation of its plant than a multiplant firm. A single-plant firm does not have to consider the implications of its move on the network of other plants; in addition, the relocation decision-making process may be far less complicated. Therefore, a positive sign is hypothesized for SEST.

Eight independent variables are used to reflect factors external to the plant that may affect the firm's relocation considerations. These variables reflect the plant's proximity to input supplies, customers, and transportation services. If labor (LABOR), customers (CUSPR), input suppliers (SUPPR), and business and professional services (BUSERPR) are regarded as important and are close to the plant (variables assigned a value of one in the dummy variable specification), firms should be less likely to consider seriously relocating the facility; therefore, a negative sign is expected for these variables. Also, if the plant consumes large amounts of water in the production process, the availability of this input at the present site (WATER) may also discourage relocation consideration. Similarly, plants located within two miles of an expressway interchange (where HIGH is equal to one) are regarded as having a relatively good level of accessibility and less likely to consider relocation.

Plants which are located near the core of the city should be more likely to consider relocation, inasmuch as central area congestion may represent an additional cost to the plant's operation. Also, land rents are typically higher and the opportunity costs of remaining on valuable central sites may be considerable. Proximity to the core (MITOCR) is measured by the present site's distance to the heart of the central business district, and its parameter is expected to have a negative sign. Finally, a firm whose plant is located in a high crime incidence area (CRIME) is hypothesized to be more likely to consider relocation as a result of higher costs of operation and difficulties with plant security; a positive sign is therefore hypothesized.

\section{ESTIMATION AND RESULTS}

The survey responses provide considerable support for the proposition that a substantial proportion of firms seriously considers relocation. 
TABLE 1

Variable Names, Definitions, and Expected Signs of Coefficients

\begin{tabular}{|c|c|c|}
\hline Variable & Definition & $\begin{array}{l}\text { Expected Sign } \\
\text { of Parameter }\end{array}$ \\
\hline \multicolumn{3}{|l|}{ Dependent: } \\
\hline CONRELOC & Equals 1 if the firm has seriously considered relocation and zero otherwise & \\
\hline \multicolumn{3}{|l|}{ Independent: } \\
\hline EMP & Number of employees at the time of the survey (December 1979) & - \\
\hline HIGROW & $\begin{array}{l}\text { Equals } 1 \text { if sales increased } 15 \text { percent or more per year over the } \\
\text { previous } 5 \text { years and zero otherwise }\end{array}$ & - \\
\hline LOGROW & $\begin{array}{l}\text { Equals } 1 \text { if sales growth was less than } 5 \text { percent per year over the } \\
\text { previous } 5 \text { years and zero otherwise }\end{array}$ & - \\
\hline CHGOPER & $\begin{array}{l}\text { Equals } 1 \text { if there had been a change in the nature of plant operations over } \\
\text { the past } 10 \text { years and zero otherwise }\end{array}$ & + \\
\hline YRATSITE & Number of years the plant has been at its present site & + \\
\hline YRATSITE*LEASE & $\begin{array}{l}\text { Product of YRATSITE and a dummy variable equal to } 1 \text { if the plant leases its } \\
\text { production space and zero otherwise }\end{array}$ & + \\
\hline EXPANDR & $\begin{array}{l}\text { Equals } 1 \text { if the plant does not have room to expand at its present site and } \\
\text { zero otherwise }\end{array}$ & + \\
\hline OPERA & $\begin{array}{l}\text { Equals } 1 \text { if the establishment can operate in a variety of buildings and } \\
\text { sites and zero otherwise }\end{array}$ & + \\
\hline
\end{tabular}


TABLE 1 (Continued)

Variable Names, Definitions, and Expected Signs of Coefficients

\begin{tabular}{|c|c|c|}
\hline Variable & Definition & $\begin{array}{l}\text { Expected Sign } \\
\text { of Parameter }\end{array}$ \\
\hline SEST & Equals 1 if the firm is a single establishment firm and zero otherwise & + \\
\hline WATER & $\begin{array}{l}\text { Equals } 1 \text { if the firm reported that water is important in its operation } \\
\text { and zero otherwise }\end{array}$ & - \\
\hline LABOR & $\begin{array}{l}\text { Equals } 1 \text { if the firm reported that proximity to labor force is important } \\
\text { and zero otherwise }\end{array}$ & - \\
\hline CUSPR & $\begin{array}{l}\text { Equals } 1 \text { if the firm reported that proximity to customers is important and } \\
\text { zero otherwise }\end{array}$ & - \\
\hline SUPPR & $\begin{array}{l}\text { Equals } 1 \text { if the firm reported that proximity to suppliers is important and } \\
\text { zero otherwise }\end{array}$ & - \\
\hline BUSERPR & $\begin{array}{l}\text { Equals } 1 \text { if the firm reported that proximity to business services is important } \\
\text { and zero otherwise }\end{array}$ & - \\
\hline HIGH & $\begin{array}{l}\text { Equals } 1 \text { if the plant is presently located within } 2 \text { miles of a freeway } \\
\text { interchange }\end{array}$ & - \\
\hline MITOCR & Number of miles from the city center to the plant's location & - \\
\hline CRIME & Number of crimes in the district in which the plant is located & + \\
\hline
\end{tabular}


Forty-two percent of the Milwaukee respondents indicated that relocation had been considered between 1972 and the time of the survey.

Probit analysis was used to estimate the relationship between the probability of considering a relocation and the independent variables. This analysis assumes that the conditional probability of considering a relocation has a normal distribution with zero mean and unit variance. The parameters resulting from the probit estimation can be used to predict a value for the dependent variable for a firm with certain characteristics or values for the independent variables. Using the fact that these predicted values have a normal distribution with zero mean and unit variance, the area under the normal distribution curve lying to the left of the predicted value of the dependent variable is the probability of considering a move [ 6 , pp. 248-251]. For the dummy (independent) variables, a variable with a large parameter implies a change in the value of that variable has a larger impact on the probability of considering a relocation than a variable with a smaller parameter. The results are reported in Table 2 . The means and standard deviations for the variables and a simple correlation matrix are given in Appendix Tables A-1 and A-2.

\section{TABLE 2}

Probit Results for Factors Affecting Relocation Consideration Among Manufacturing Establishments in Milwaukee City ${ }^{\mathrm{a}}$

\begin{tabular}{|c|c|c|c|}
\hline Variable & $\begin{array}{l}\text { Hypothesized } \\
\text { Sign }\end{array}$ & Coefficient & $t$-value ${ }^{b}$ \\
\hline CONSTANT & & 18.985 & 2.70 \\
\hline EMP & - & -0.056 & 3.04 \\
\hline HIGROW & - & -4.162 & 2.06 \\
\hline LOGROW & - & -30.461 & 3.86 \\
\hline CHGOPER & + & -13.473 & 3.46 \\
\hline YRATSITE & + & 0.124 & 2.43 \\
\hline YRATSITE*LEASE & + & 0.111 & 2.22 \\
\hline EXPANDR & + & 11.012 & 3.29 \\
\hline OPERA & + & 13.474 & 3.46 \\
\hline SEST & + & 6.446 & 2.40 \\
\hline WATER & - & 10.603 & 3.53 \\
\hline LABOR & - & -0.620 & 0.42 \\
\hline CUSPR & - & -10.974 & 3.23 \\
\hline SUPPR & - & 1.663 & 0.80 \\
\hline BUSERPR & - & -6.681 & 2.61 \\
\hline $\mathrm{HIGH}$ & - & -13.155 & 3.30 \\
\hline MITOCR & - & -2.292 & 3.68 \\
\hline CRIME & + & 0.0005 & 1.00 \\
\hline Log Likelihood Ratio ${ }^{c}$ & & 54.178 & \\
\hline
\end{tabular}



'The absolute values of the t-ratios are reported.

'In separate OLS analysis, an $\mathrm{R}^{2}$ of .54 was obtained. 
Only three of the 17 coefficients do not have their hypothesized signs; these are the coefficients for change in operations (CHGOPER), proximity to suppliers (SUPPR), and whether or not the plant uses substantial inputs of water (WATER). Three variables have coefficients that are not statistically different from zero; these are proximity to labor (LABOR), proximity to suppliers (SUPPR), and the amount of crime (CRIME).

Variables that hold firms at existing locations and those that give firms an impetus to consider relocation can be identified from the coefficients that are statistically significant and also have the expected sign. The results show that larger firms (measured by number of employees) are less likely to contemplate relocation than a firm with fewer employees. Firms with low growth rates are less likely to consider relocation than higher growth rate firms, but having neither a high growth rate nor a low growth rate (medium growth rate is excluded from the analysis) gives a firm a positive impetus to consider relocation. This finding may be interpreted as suggesting that low growth rate plants are "locked in" to existing locations due to difficulties in raising investment capital because of poor performance and a relatively unhealthy financial picture, while high growth rate establishments are reluctant to risk the disruptions and costs of moving a successful operation.

Proximity to customers and to business services at the plant's present location are strong deterrents to considering relocation. Access to an expressway interchange at the present site is also a strong deterrent to considering relocation. Plants which are located farther from the CBD are less likely to consider relocation, most probably because they are not so near the congestion and high land prices of the CBD.

In contrast, the presence of several other factors increases the probability that a firm will consider relocating its plant. The longer the firm has been at its present site, the greater the probability of its considering a move. Firms that do not own their own production space are more likely to consider a move the longer they have occupied their present sites. Lack of room for expansion gives a firm strong impetus to relocate its production facilities. This finding is consistent with Schmenner's [15] findings about the importance of on-site expansion space to firms. Firms whose operations can utilize any type of building are also much more likely to consider relocation than those plants requiring specialized production space. Single plant firms are also much more likely to consider relocation than multiplant firms.

The coefficients of two variables have signs opposite those that were hypothesized and are also statistically different from zero. Plants that have changed their operations are apparently, at least in this sample of establishments, less likely to contemplate relocation. A change in the nature of operations may therefore imply that such plants can successfully make the adjustment to the change in operations provided that they have adequate room for expansion on-site and other factors do not induce them to consider relocation. The second variable with a sign opposite that hypothesized and statistically significant from zero is WATER. The analysis indicates that firms with plants that use substantial inputs of water 
are more likely to consider relocation. Lower costs for water elsewhere in the metropolitan area may account for this finding or these firms may be induced to consider relocation because of more stringent anti-pollution regulations.

\section{CONCLUSIONS}

From the results obtained here, profiles of potential mover plants and non-mover plants emerge. If central city policy-makers can identify firms contemplating a relocation of their plants and their reasons for considering movement, policies may be developed to help retain existing plants and foster their expansion.

Firms whose plants have occupied the same site for a long time, have no or little room for expansion, are single plant establishments and can operate in any type of building(s) are most likely to consider relocation. Also, firms whose plants are located nearer to the core of the city are more likely to consider relocation although relocation consideration does not appear, at least from our analysis, to be significantly affected by a higher incidence of crime. ${ }^{7}$ On the other hand, firms that are near their customers, near business services, and have access to expressway interchanges are less likely to contemplate relocation.

On the basis of the size of the estimated parameters, it may be concluded that internal factors influencing relocation consideration are at least as important as external ones. Unfortunately, public policy strategies are very limited in terms of approaches that may address this array of factors. As Schmenner [16] concludes, central city agencies wanting to retain industry might try to assemble land for plants that want to expand their operations at existing sites. If this is not possible, these development agencies might identify cleared land (or clear land although this is risky without a location commitment from firms) near highway interchanges where firms can relocate with enough space for future expansion. The sites should preferably be close to the present sites of these potentiallyrelocating plants inasmuch as many firms value the proximity of their plants to customers and business services.

The question of what turns a firm considering relocation into a mover is a logical extension of this analysis. While this question cannot be definitely answered using this data set, some conjecture is possible. A majority of the surveyed firms which seriously considered moving indicated that they had remained at their present sites because of a large investment in facilities not yet amortized and difficult to sell. Once the existing facilities have been depreciated, the advantages of a new site with room for expansion and incorporating new technologies must be weighed against the costs of severing established ties in labor and product markets. 


\section{FOOTNOTES}

${ }^{1}$ In this paper the terms "plant" or "establishment" refer to a single production operation. A "firm" or "enterprise" may consist of one or more plants or establishments. The term "firm" is used in the context of the decision-making process concerning an individual plant. ${ }^{2}$ Struyk and James [22] compared the number of relocating establishments over the 1965-1968 period to the 1965 base number of establishments in each of four SMSA's, deriving the following percentages of establishments which relocated: Cleveland-13.8\%; Minneapolis-St. Paul-15.9\%; Boston-9.8\%; and Phoenix-8.9\%.

${ }^{3}$ Gruber's [7] analysis is confined to cross-tabulations of reported data and, as such, no tests of statistical significance between groups are available.

${ }^{4}$ The questionnaire used in the survey is available from the authors upon request.
${ }^{5}$ Respondents were asked to answer "yes" or "no" to the following question: Since 1972, has your establishment seriously contemplated relocation?

${ }^{6}$ Additional information on the designation of these districts can be found in Erickson [1980].

${ }^{7}$ An open-ended question inquired about any aspects of the existing site that were a disappointment. The vast majority of respondents identified problems with the buildings (usually "too small," "insufficient room for expansion," "multi-storied building inefficient," etc.). Nine respondents mentioned deteriorating neighborhoods surrounding the plant, with five citing crime (generally vandalism) as a disappointment. Yet, only three of the nine firms had seriously considered relocation.

\section{REFERENCES}

1. Berry, B. J. L. and Y. S. Cohen. "Decentralization of Commerce and Industry: The Restructuring of Metropolitan America," in L. H. Masotti and J. K. Hadden, eds., The Urbanization of the Suburbs. Beverly Hills: Sage Publications, 1973. pp. 431-455.

2. Christian, C. M. and S. J. Bennett. "Industrial Relocations from the Black Community of Chicago," Growth and Change, 4, 2 (April 1973): 14-20.

3. Dicken, P. "The Multiplant Business Enterprise and Geographical Space: Some Issues in the Study of External Control and Regional Development," Regional Studies, 10 (1976): 402-412.

4. Erickson, R. A. "Environment as 'Push Factor' in the Suburbanization of Business Establishments," Urban Geography, 1, 2 (June 1980): 167-178.

5. Erickson, R. A. and M. Wasylenko. "Firm Relocation and Site Selection in Suburban Municipalities," Journal of Urban Economics, 8, 1 (July 1980): 69-85.

6. Goldberger, A. S. Econometric Theory. New York: Wiley, 1964.

7. Gruber, J. "Central City Manufacturing Firms: Who is Leaving and Why," in A. M. Hamer, ed., Urban Atlanta: Redefining the Role of the City. Research Monograph 84, Atlanta: Georgia State University, 1980. pp. 61-78.

8. Hamer, A. M. Industrial Exodus From Central City: Public Policy and the Comparative Costs of Location. Lexington: D. C. Heath and Company. 1973.

9. James, F. J., Jr. and J. W. Hughes. "The Process of Employment Location Change: An Empirical Analysis," Land Economics, 49, 4 (November 1973): 404-413.

10. Kain, J. F. "The Distribution and Movement of Jobs and Industry," in J. Q. Wilson, ed., The Metropolitan Enigma. New York: Doubleday, 1970. pp. 1-43.

11. Luttrell, W. F. Factory Location and Industrial Movement: A Study of Recent Experience in Great Britain, $\mathrm{Vol}$. 2. London: National Institute of Economic and Social Research, 1962.
12. Mandell, L. Location Decisions: Detroit Compared with Atlanta and Chicago. New York: Praeger Publishers, 1975.

13. Mills, E. S. Studies in the Structure of the Urban Economy. Baltimore: Johns Hopkins Press, 1972.

14. Moses, L. N. and H. F. Williamson, Jr. "The Location of Economic Activity in Cities," American Economic Review, 57, 2 (May 1967): 211-222.

15. Schmenner, R. W. The Manufacturing Location Decision: Evidence from Cincinnati and New England. Economic Development Research Report, Washington, D. C.: Economic Development Administration, 1978.

16. Schmenner, R. W. "Industrial Location and Urban Policy Management," in A. Solomon, ed., Industrial Location and Urban Public Management. London: MIT Press, 1980. pp. 446-468.

17. Schmenner, R. W. "Choosing New Industrial Capacity: On-Site Expansion, Branching, and Relocation," Quarterly Journal of Economics, 95, 1 (February 1980): 103-119.

18. Schmidt, C. G. "An Analysis of Firm Relocation Patterns in Metropolitan Denver, 1974-1976," $A n$ nals of Regional Science, 13, 1 (March 1979): 78-91.

19. Sperling, J. and M. Russo. "Company Relocation: Is the Grass Greener," Management Review 60, 4 (April 1971): 28-32.

20. Steed, G. P. F. "Standardization, Scale, Incubation and Inertia: Montreal and Toronto Clothing Industries," Canadian Geographer, 20, 3 (Fall 1976): 298309.

21. Struyk, R. J. "Evidence on the Locational Activity of Manufacturing Industries in Metropolitan Areas," Land Economics, 48, 4 (November 1972): 377-382.

22. Struyk, R. J. and F. J. James, Jr. Intrametropolitan Industrial Location. Lexington: D. C. Heath and Company, 1975.

23. Townroe, P. M. "Locational Choice and the Individual Firm," Regional Studies, 3 (1969): 15-24. 


\section{APPENDIX}

TABLE A-1

Summary Statistics for the Dependent and Independent Variables

\begin{tabular}{lrr}
\hline \multicolumn{1}{c}{ Variable } & Mean & $\begin{array}{r}\text { Standard } \\
\text { Deviation }\end{array}$ \\
\hline Dependent: & & \\
CONRELOC & 0.42 & 0.50 \\
Independent: & & \\
EMP & 98.12 & 276.89 \\
HIGROW & 0.18 & 0.39 \\
LOGROW & 0.27 & 0.45 \\
CHGOPER & 0.65 & 0.48 \\
YRATSITE & 34.56 & 22.63 \\
YRATSITE*LEASE & 10.18 & 21.38 \\
EXPANDR & 0.80 & 0.40 \\
OPERA & 0.29 & 0.46 \\
SEST & 0.86 & 0.35 \\
WATER & 0.31 & 0.47 \\
LABOR & 0.67 & 0.48 \\
CUSPR & 0.27 & 0.45 \\
SUPPR & 0.25 & 0.44 \\
BUSERPR & 0.45 & 0.50 \\
HIGH & 0.84 & 0.37 \\
MITOCR & 3.51 & 2.64 \\
CRIME & 1013.04 & 888.67 \\
\hline
\end{tabular}


TABLE A-2

Correlation Matrix for the Dependent and Independent Variables

\begin{tabular}{|c|c|c|c|c|c|c|c|c|c|c|c|c|c|c|c|c|c|}
\hline & EMP & HIGROW & LOGROW & CHGOPER & YRATSITE & LEASE & EXPANDR & OPERA & SEST & WATER & LABOR & CUSPR & SUPPR & BUSERPR & R HIGH & MITOCR & CRIME \\
\hline CONRELOC & -0.13 & 0.14 & $-0.34^{*}$ & -0.22 & 0.18 & 0.18 & 0.01 & 0.17 & -0.01 & 0.21 & 0.08 & 0.02 & -0.12 & -0.12 & 0.25 & $-0.39 *$ & $0.27 *$ \\
\hline EMP & & -0.07 & -0.12 & 0.12 & $0.35^{*}$ & $0.55^{*}$ & 0.05 & -0.09 & -0.37 & -0.08 & -0.19 & -0.11 & -0.13 & -0.15 & $-0.32^{*}$ & -0.14 & 0.19 \\
\hline HIGROW & & & $-0.28^{*}$ & 0.13 & -0.20 & -0.03 & -0.03 & 0.04 & 0.04 & -0.20 & 0.11 & -0.17 & 0.20 & 0.10 & -0.08 & -0.07 & 0.08 \\
\hline LOGROW & & & & -0.19 & 0.17 & -0.02 & $0.30^{*}$ & 0.08 & 0.24 & -0.04 & -0.22 & 0.02 & 0.04 & -0.12 & -0.10 & 0.01 & -0.19 \\
\hline CHGOPER & & & & & -0.14 & -0.09 & 0.05 & 0.03 & -0.06 & -0.12 & -0.17 & -0.10 & -0.04 & -0.16 & 0.02 & -0.06 & 0.13 \\
\hline YRATSITE & & & & & & $0.42^{*}$ & $0.32^{*}$ & -0.17 & $-0.31^{*}$ & 0.08 & -0.24 & 0.05 & -0.14 & -0.21 & -0.03 & $-0.30^{*}$ & 0.22 \\
\hline YRATSITE*LEASE & & & & . & & & 0.08 & -0.03 & -0.13 & -0.02 & -0.03 & -0.09 & -0.20 & 0.05 & -0.16 & $-0.36^{*}$ & 0.18 \\
\hline EXPANDR & & & & & & & & -0.01 & -0.05 & 0.01 & -0.03 & $0.30^{*}$ & -0.05 & -0.15 & 0.06 & -0.17 & 0.21 \\
\hline OPERA & & & & & & & & & 0.26 & -0.07 & 0.00 & -0.20 & -0.08 & 0.19 & 0.16 & -0.11 & -0.06 \\
\hline SEST & & & & & & & & & & -0.22 & 0.32 & -0.01 & 0.23 & 0.25 & -0.02 & 0.14 & -0.17 \\
\hline WATER & & & & & & & & & & & -0.06 & 0.34 & 0.01 & 0.19 & 0.18 & -0.13 & -0.10 \\
\hline LABOR & & & & & & & & & & & & 0.16 & 0.13 & $0.47^{*}$ & 0.04 & 0.12 & -0.17 \\
\hline CUSPR & & & & & & & & & & & & & 0.25 & 0.15 & 0.02 & -0.09 & -0.10 \\
\hline SUPPR & & & & & & & & & & & & & & $0.37 *$ & -0.12 & 0.08 & -0.08 \\
\hline BUSERPR & & & & & & & & & & & & & & & -0.15 & 0.14 & -0.10 \\
\hline $\mathrm{HIGH}$ & & & & & & & & & & & & & & & & $-0.35^{*}$ & 0.13 \\
\hline MITOCR & & & & & & & & & & & & & & & & & $-0.56^{*}$ \\
\hline
\end{tabular}

*indicates statistical significance at the 0.05 level $\mathrm{nr}$ better 